\title{
Regular exercise reduces fibrinogen levels: a review of longitudinal studies
}

\author{
E. Ernst \\ Department of Physical and Medical Rehabilitation, AKH, University of Vienna Medical School, Austria
}

\begin{abstract}
Fibrinogen can be considered as a major cardiovascular risk factor. Therefore there is a growing interest in methods to lower its plasma level. This paper is aimed at reviewing the data investigating the effects of regular exercise on plasma fibrinogen levels. Cross-sectional studies strongly suggest that regular exercise will reduce fibrinogen levels, and longitudinal data confirm this. The average decrease achieved by regular endurance exercise over several months is around $0.4 \mathrm{~g} / \mathrm{l}$. It can be extrapolated that this corresponds to a substantial decrease in risk of coronary heart disease. It is concluded that regular exercise is the most practicable approach known to date to lower plasma fibrinogen levels.
\end{abstract}

Keywords: Fibrinogen, cardiovascular risk, exercise, physical medicine

A wealth of data has accumulated during the last decade to suggest that fibrinogen represents an independent cardiovascular risk factor. Its impact seems to be as strong as, or even stronger than, that of total cholesterol ${ }^{1}$. If this view is accepted, the question arises as to how fibrinogen levels can be altered in order to reduce the risk. Clearly this aspect has not yet been fully investigated.

Obviously simple lifestyle changes would be preferable to medication. Yet at present our knowledge about factors that do affect fibrinogen is incomplete. Stopping smoking will have a substantial fibrinogen-lowering effect ${ }^{2}$. Diet seems to have surprisingly little influence ${ }^{1}$. Psychological stress may be more important, and being overweight may also be relevant ${ }^{3}$.

A prime candidate among lifestyle variables to alter the cardiovascular risk is exercise. It seems timely therefore to review the data relevant to the question of whether regular exercise modifies fibrinogen levels.

\section{Cross-sectional data}

Several epidemiological studies have suggested that exercise does modify fibrinogen levels. For instance, both the Whitehall ${ }^{4}$ and the Gothenborg studies ${ }^{5}$

Address for correspondence: E. Ernst, Department of Physical and Medical Rehabilitation, AKH, Währinger Gürtel 18-20, A-1090 Vienna, Austria

(C) 1993 Butterworth-Heinemann Ltd 0306-3674/93/030175-02 found an inverse relationship between physical activity and fibrinogen. In the Scottish Heart Health Study of 8824 men and women, individuals who were inactive in leisure time or at work had significantly higher fibrinogen levels compared with more physically active study participants ${ }^{6}$. Recently Connelly and co-workers addressed the problem by comparing individuals with a history of no, mild or strenuous exercise ${ }^{7}$. These authors clearly showed that strenuous exercise is associated with a reduction of fibrinogen even if age, smoking habits, alcohol consumption, body mass index and occupation (manual or non-manual) are accounted for. The most comprehensive cross-sectional study is the Arteriosclerosis Risk in Communities study ${ }^{8}$. It extrapolates that 1 unit of sportive activity would reduce the fibrinogen level by $0.3-0.4 \mathrm{~g} / \mathrm{l}$.

\section{Longitudinal studies}

Evidence from cross-sectional data, by definition, is limited as to its conclusiveness; in particular it is not possible to establish a cause-effect relationship?. Therefore longitudinal trials are needed to answer the above question.

The first such study was published in Russian ${ }^{10}$ and all we know about its findings is that 30 patients with coronary heart disease were submitted to a 30 -day regimen of regular exercise. This brought about a significant drop in fibrinogen levels. Neither the degree of change nor the results from the control group are mentioned in the English abstract of this paper. Therefore the study cannot be interpreted conclusively.

Stratton et al. ${ }^{11}$ published a study in which two different groups of men were submitted to endurance exercises of increasing intensity for 6 months. One group was composed of young men (24-30 years old), while the other was composed of elderly men (60-82 years old). All were healthy according to a physical and routine laboratory check-up. Fibrinogen was measured by the Clauss method before and after the programme. To exclude interference of acute phase responses due to intercurrent infections, the C-reactive protein was also measured. It did not change during the trial. Fibrinogen, however, decreased by $13 \%$ in the group of young men. The group of elderly men showed a non-significant trend in the same direction. 
Table 1. Controlled trials on exercise and fibrinogen

\begin{tabular}{|c|c|c|c|}
\hline First author (design) & Study populations & Exercise programme & Fibrinogen change \\
\hline Stratton & $\begin{array}{l}10 \text { healthy young men } \\
13 \text { healthy elderly men }\end{array}$ & $\begin{array}{l}\text { Four or five times }(45 \mathrm{~min}) \text { per week, } 4 \\
\text { months at } 50-60 \% \text { heart rate reserve, } \\
\text { then } 2 \text { months at } 80-85 \% \text { heart rate } \\
\text { reserve, endurance exercise }\end{array}$ & $\begin{array}{l}\text { Young: from } 2.3(0.5)^{*} \text { to } 2.2(0.5) \\
\text { (n.s.) } \\
\text { Elderly: from } 3.6(0.8) \text { to } 3.1(0.5)(P= \\
0.002)\end{array}$ \\
\hline Wosornut (randomized) & $\begin{array}{l}55 \text { men, } 12 \text { months after } \\
\text { coronary artery surgery }\end{array}$ & $\begin{array}{l}\text { Three times }(12-60 \mathrm{~min}) \text { per week } \\
\text { 1. Aerobic exercise }(n=15) \\
\text { 2. Power exercise }(n=20) \\
\text { 3. No exercise }(n=20)\end{array}$ & $\begin{array}{l}\text { 1. From } 3.4(0.2) \text { to } 3.0(0.2)(P=0.02) \\
\text { 2. From } 3.2(0.1) \text { to } 3.1(0.1) \text { (n.s.) } \\
\text { 3. From } 3.5(0.2) \text { to } 3.3(0.2) \text { (n.s.) }\end{array}$ \\
\hline Ernst & $\begin{array}{l}24 \text { healthy sedentary } \\
\text { volunteers }\end{array}$ & $\begin{array}{l}\text { 1. } 28 \mathrm{~h} \text { per week endurance exercise } \\
(n=12) \text { for } 9 \text { weeks } \\
\text { 2. No exercise }(n=12)\end{array}$ & $\begin{array}{l}\text { 1. } 2.6(0.3) \text { to } 2.2(0.4)(P<0.05) \\
\text { 2. (n.s.) }\end{array}$ \\
\hline
\end{tabular}

n.s., not significant, all studies were conducted according to a parallel group design; *Values are mean(s.d.); †The only randomized trial on the subject

Wosornu and co-workers ${ }^{12}$ randomized 55 men within 12 months of coronary artery surgery into three groups: controls did not exercise, one experimental group performed regular aerobic exercises, and another one carried out regular power exercises, both for a period of 6 months. Each session lasted for $12-60 \mathrm{~min}$ and was repeated three times weekly for 6 months. The intensity of the exercise was not defined but seemed to be at a medium level. Only aerobic exercise was associated with a significant decrease of fibrinogen levels (Table 1).

Our group submitted 12 healthy volunteers to regular endurance exercises. The programme comprised $28 \mathrm{~h}$ of exercise (medium intensity) per week and lasted for 9 weeks. At the end of the trial period fibrinogen had dropped significantly, while it remained stable in unexercised controls ${ }^{13}$.

Similar results were obtained in patients suffering from intermittent claudication ${ }^{14}$. Yet in this study only plasma viscosity was determined which is only a rough estimate for fibrinogen. Baseline values were elevated in claudicants and were normalized within 2 months by regular (five times per week) walking exercise. This effect was paralleled by an increase in walking ability.

These studies agree that endurance exercise for several weeks will decrease fibrinogen. The absolute fall is surprisingly uniform in the region of $0.4 \mathrm{~g} / \mathrm{l}$. On the basis of the data of the Northwick Park Heart study $^{15}$, in which the strength of the association of fibrinogen and coronary heart disease is characteristic of other epidemiological prospective studies ${ }^{1}$, one can calculate ${ }^{7}$ that $0.1 \mathrm{~g} / \mathrm{l}$ difference corresponds to a modification of coronary heart disease risk of $15 \%$. Thus a decrease of $0.4 \mathrm{~g} / \mathrm{l}$ could mean a decrease in risk of as much as $60 \%$.

\section{Discussion}

Exercise has often been shown to protect against coronary heart disease. Several mechanisms have been discussed - among others blood lipids, blood pressure, insulin levels and obesity. The data reviewed above suggest that the reduction of fibrinogen is yet another factor to be considered.
Fibrinogen is a cardiovascular risk factor through its participation in both the atherogenic and thrombogenic processes ${ }^{1}$. Exercise may be the most appropriate way known to date to lower plasma fibrinogen concentrations.

\section{References}

1 Ernst E, Koenig W, Lowe GDO, Meade TW. Fibrinogen, a 'New' Cardiovascular Risk Factor. Oxford, UK: Blackwell, 1992.

2 Ernst E, Matrai A. Abstention from chronic cigarette smoking normalizes blood rheology. Atherosclerosis 1987; 64: 75-7.

3 Ernst E, Weihmayr T, Schmid M, Baumann M, Matrai A. Cardiovascular risk factors and hemorheology. Physical fitness, stress and obesity. Atherosclerosis 1986; 59: 263-9.

4 Morris JN, Clayton DG, Everitt MG, Semmence AM, Burgess $\mathrm{EH}$. Exercise in leisure time: coronary attack and death rates. Br Heart J 1990; 63: 325-34.

5 Rosengren A, Wilhelmsen L, Welin T, Tsipogianni A, Teger-Nilsson AC, Wedel $\mathrm{H}$. Social influences and cardiovascular risk factors as determinants of plasma fibrinogen concentration in a general population sample of middle aged men. $\mathrm{Br}$ Med I 1990; 300: 634-8.

6 Lee AJ, Smith WCS, Lowe GDO, Tunstall-Pedoe H. Plasma fibrinogen and coronary risk factors: The Scottish Heart Health Study. J Clin Epidemiol 1990; 9: 913-9.

7 Connelly JB, Cooper JA, Meade TW. Strenuous exercise, plasma fibrinogen, and factor VII activity. Br Heart J 1992; 67: 351-4.

8 Folsom AR, Wu KK, Davis CE, Conlan MG, Sorlie PD, Szklo M. Population correlates of plasma fibrinogen and factor VII, putative cardiovascular risk factors. Atherosclerosis 1991; 91: 191-205.

9 Anderson B. Methodological Errors in Medical Research. Oxford, UK: Blackwell, 1990.

10 Dudaev VA, Dyukov IV, Borodkin VV et al. Change of the level of fibrinogen and its high molecular derivatives as a result of physical training in CHD patients. Ter Arkh 1986; 58: 62-6.

11 Stratton JR, Chandler WL, Schwartz RS. Effects of physical conditioning on fibrinolytic variables and fibrinogen in young and old healthy adults. Circulation 1991; 83: 1692-7.

12 Wosornu D, Allardyce W, Ballantyne D, Tansey P. Influence of power and aerobic exercise training on haemostatic factors after coronary artery surgery. Br Heart $J$ 1992; 68: 181-6.

13 Ernst E, Schmid M. Regular aerobic exercise lowers fibrinogen levels. Eruop J Phys Med Rehab (in press).

14 Ernst E, Matrai A. Intermittent claudication, exercise and blood rheology. Circulation 1987; 76: 1110-14.

15 Meade TW, Mellows S, Brozovic $M$ et al. Haemostatic function and IHD: principal results of the Northwick Park Heart Study. Lancet 1986; ii: 533-7. 